\title{
Students as facilitators in a teacher training program: motivation for leadership roles
}

This article was published in the following Dove Press journal:

Advances in Medical Education and Practice

13 November 2015

Number of times this article has been viewed

\author{
Annette Burgess' \\ Christie van Diggele ${ }^{2}$ \\ Craig Mellis' \\ 'Sydney Medical School - Central, \\ The University of Sydney, Sydney, \\ NSW, Australia; ${ }^{2}$ Sydney Medical \\ School, The University of Sydney, \\ Sydney, NSW, Australia
}

Correspondence: Annette Burgess Central Clinical School, Sydney Medical School, The University of Sydney, Building 63, level 4, Royal Prince Alfred Hospital, Missenden Road,

Camperdown NSW 2050, Australia

Tel +6I $295 I 5$ 8I72

Email annette.burgess@sydney.edu.au
Introduction: Although students often partake in peer-teaching activities during medical school, they are rarely provided with formal training in teaching. We have previously described our teacher training (TT) program for medical students. The TT program is delivered faceto-face across two sessions. In order to alleviate academic teaching load required to run the course, and at the same time provide our final-year students with practical opportunities to develop their leadership skills, we engaged five senior students as co-facilitators alongside academic staff. By developing an understanding of our students' motivation to participate as facilitators, we may be able to promote an interest within leadership in teaching among other students. Our study sought to examine students' motivation to take part as facilitators in the TT program.

Methods: Data were collected through a focus group session with the five student facilitators. Self-determination theory, which poses that there are three elements key to intrinsic motivation, including autonomy, competence, and relatedness, was used as a conceptual lens to identify and code recurrent themes in the data.

Results: Elements that motivated students to assist in facilitation included an opportunity to review and build on their knowledge and skills in teaching practices; the recognition and acknowledgement received from school staff and fellow students; the opportunity to develop these relationships; and a desire to increase their peer-teaching responsibilities.

Conclusion: By actively involving our students in leadership practices, we were able to not only engage the students, but also develop our student community and contribute to the promotion of a culture of excellence in teaching within the hospital.

Keywords: teacher training, motivation, leadership, peer-assisted learning

\section{Introduction}

Although students often partake in peer-teaching activities during medical school, they are rarely provided with formal training in teaching. ${ }^{1}$ We have previously described our teacher training (TT) program for medical students. ${ }^{2}$ The purpose of the program is to assist senior students in preparation for their roles as peer teachers within medical $\mathrm{school}^{3,4}$ and also to better prepare them for their future roles as medical practitioners with teaching, supervision, and assessment responsibilities. ${ }^{5}$ The TT program is delivered face-to-face, with topics including skills teaching, small group teaching, bedside teaching, assessment, and feedback. Implemented across two 3-hour sessions, delivery includes both large group interactive teaching and small group active learning. The program is resource-intensive to run, requiring at least seven facilitators for each session, in particular for the small group activities. 
In order to alleviate the academic teaching load required to run the course, and at the same time to provide our final-year (year 4) students with practical opportunities to develop their leadership skills, we engaged a core group of students as cofacilitators of our TT program alongside two academic staff. While traditional approaches to development of leadership skills involve "courses" in leadership, it has been suggested that development of leadership skills should be addressed within the early stages of medical education and continued throughout a doctor's career. ${ }^{6}$ Further, this development should be nurtured and supported by the organization in which they learn and work. ${ }^{6}$ These newly created leadership roles, we felt, would highlight for students the importance of promoting excellence in teaching skills within the medical profession. ${ }^{7}$

By developing an understanding of students' motivation to assume such roles, we may be able to promote an interest within leadership in teaching among other students. Motivation has been described as a person's willingness to apply effort in order to achieve a particular goal, ${ }^{8}$ but it is a complex concept. While both extrinsic and intrinsic motivators are evident, intrinsic motivation is a powerful influence. ${ }^{9}$ Self-determination theory $\left(\right.$ SDT) ${ }^{9}$ offers a conceptual lens to view facilitators' intrinsic motivation. SDT poses that three elements are key to intrinsic motivation: autonomy, competence, and relatedness. Autonomy relates to students' sense of independence and choice. Competence relates to students' aim to gain mastery of a subject. Relatedness refers to students' sense of community among others with similar interests.

Our study sought to examine students' motivation to take part as facilitators in the TT program.

\section{Methods}

\section{Context}

The TT program was conducted in March 2014 at Sydney Medical School - Central, based at Royal Prince Alfred Hospital (Camperdown, NSW, Australia), where year 3 and year 4 students gain clinical experience in their final 2 years of the graduate-entry medical program. Participants enrolled in the program were from year 3 of the medical program and facilitators were from year 4 .

\section{Structure and content of the program}

The program was run across two 3-hour sessions. In total, 23 year 3 students voluntarily participated in the program. The program was delivered as a four-module face-to-face program, providing theoretical background, practical examples, and active participation in "skills teaching", "small group teaching", "clinical teaching", and "assessment and feedback". ${ }^{2}$ Facilitation included interactive large-group PowerPoint presentations as well as two small-group sessions. Each small-group session consisted of three to four participants. During the small-group sessions, participants were required to teach their peers a short 5-10 minute microteaching activity. The first activity was to teach a nonmedical skill and the second activity was a teaching presentation on a medical topic. Participants were required to provide feedback to their peers during the small-group sessions.

\section{Facilitators}

Two senior academic staff led facilitation. In total, at least seven facilitators were required to run the sessions, including the two senior academic facilitators. We invited eight of our year 4 students by email to assist in facilitation, and in particular, to supervise the small-group sessions. Students selected to facilitate were those with a good academic record, with a good attendance and participation record, and who had previously completed the TT program themselves as year 3 students. We limited the initial invitation to eight students as we felt that five to eight students would provide adequate resources, and we were unsure of the likely response.

\section{Facilitator responsibilities}

Although the senior academic staff (two associate deans) led the large group sessions, the students had minor roles within these sessions, such as speaking to some of the PowerPoint slides and demonstrating the teaching of a skill. Student facilitators had independent responsibilities for facilitation of their own small groups. They were required to facilitate each student in teaching a skill within the group, give a short tutorial, and ensure correct feedback by other members of the group (as well as their own feedback). Students were thanked by the associate dean of the school and given a certificate at the end of the course.

To prepare for their facilitator roles, students were required to attend a 1-hour meeting where they were briefed on their responsibilities and how to teach within the small groups and were provided with facilitator packages containing the PowerPoint presentations, facilitator guidelines, and a detailed schedule.

\section{Data collection and analysis}

Student facilitators were invited to attend a focus group. Data were transcribed verbatim. A thematic analysis of the qualitative data was done using Framework Analysis. ${ }^{10}$ SDT was used as the conceptual framework for this paper and to subsequently develop a thematic framework, which was 
Table I Students' motivation in relation to autonomy

\begin{tabular}{|c|c|}
\hline Themes relating to autonomy & Student comments \\
\hline Student liked being approached directly to facilitate & $\begin{array}{l}\text { "I liked that the email asking me to facilitate was personalized, in a targeted approach. } \\
\text { The personalized aspect inspired me to respond. Having been asked directly, I thought } \\
\text { I should get involved. There is also a sense of obligation. I did the program last year } \\
\text { and I really enjoyed it, so I wanted to help out". } \\
\text { "I got the impression it was a limited email that was sent around, and that we were } \\
\text { approached directly, I appreciated that personally. I immediately replied". }\end{array}$ \\
\hline $\begin{array}{l}\text { Students enjoyed the autonomy of having their own } \\
\text { small groups to facilitate }\end{array}$ & $\begin{array}{l}\text { "I enjoyed the small groups the best. I felt responsible and a sense of achievement. } \\
\text { I don't think we've ever really run small groups before, so it was a good opportunity } \\
\text { to practice leadership skills, to also practice engaging people you're trying to teach, } \\
\text { like how to make something interesting, not boring". }\end{array}$ \\
\hline $\begin{array}{l}\text { Students indicated that they would have liked } \\
\text { greater responsibility and autonomy throughout } \\
\text { the large-group sessions }\end{array}$ & $\begin{array}{l}\text { "I would like more opportunities to present in the future during the large group } \\
\text { sessions, and even in organizing the training. But it is good to start with a small role } \\
\text { and develop that". } \\
\text { "It provided a sense of autonomy when the professor came up to us and said, 'So are } \\
\text { you doing these slides too?' It's nice that we are seen as confident enough to do that". }\end{array}$ \\
\hline
\end{tabular}

Table 2 Students' motivation in relation to competence

Theme relating to competence
Through facilitation, students were able to
revise teaching concepts they had previously learn
Facilitation was a way for students to reinforce
their own teaching knowledge and skills

Facilitation was a way for students to re
their own teaching knowledge and skills

Facilitation helped to develop students' communication skills

Students felt facilitation would help them prepare for their roles as medical practitioners and also provide evidence of their experience

Students found a sense of satisfaction and mastery in running their own small groups

Students gained a sense of achievement and recognition

Students wanted to improve the quality of teaching

Students learnt there are many skills involved in teaching that require practical experience to master

Students were able to gain confidence from facilitating

\section{Student comments}

"I thought being a facilitator would help revise all the concepts that I learnt last year. I revised all these concepts, and practiced on presentation skills".

"Being a facilitator means I can use all the skills about feedback and teaching a skill, all the different steps".

"When we were teaching in the small groups, we had to keep reminding the students about, for example, the steps in feedback, and reminding the students what the rules were, and you were actually reminding yourself as well".

"Facilitating gives a reason for us to actually dig deeper into topics that we should know about, it reminds me about what I don't know. You have to understand the concepts of teaching a lot more in order to teach it".

"When you are teaching younger peers you have to consolidate information that you've learnt and it also improves your communication skills because you're trying to convey succinctly a concept, so I would have thought that would be very useful in terms of developing my skills as a doctor".

"I thought it would help in that I'm hoping to do some teaching next year as an intern, so that would be good preparation, and something good to add to my CV".

"I think it is of benefit on your CV if you're an intern or a resident. Maybe they would have faith that you'd be teaching students properly".

"There is always a sense of satisfaction when you've done something properly and I think just from the small-group sessions that we did, I felt pretty satisfied that they went well and accomplished what we were trying to get out of the whole session".

"I felt a sense of achievement being a facilitator. The certificate of being a facilitator is important".

"Because you feel like you've judged other people as teachers in the past, you want to not fall into their mistakes. So I think mastering the art of teaching is important to us". "How to deal with people not following instructions, it can be frustrating. When they are teaching a skill, and doing it in the wrong order, you have to figure out how to correct people. That is just as important as being able to explain something in the first place, because we can all explain how to do something, but then to actually correct someone who thinks they're doing it right is hard. And you need to understand why they are doing it wrong as well. You need to be a good observer in this type of thing. And you need to see where their thought process is going wrong".

"I think having been a facilitator, l'd feel more confident in explaining something to others, which is a pretty important part of being a doctor in general; you're going to have to explain every day different things to patients".

"I think teaching is less difficult if you've facilitated in this course".

Abbreviation: $\mathrm{CV}$, curriculum vitae. 
applied to a portion of the dataset by two authors to determine its trustworthiness. Subsequently, a coding framework was developed to code the entire dataset in order to identify and code recurrent themes in the data. ${ }^{10}$

Ethics approval was obtained from the University of Sydney Human Research Ethics Committee.

\section{Results}

Of the eight students who were invited to be facilitators, five agreed to participate.
All five student facilitators attended the focus group. Of the five, four were female and one was male.

Using the components of SDT, including autonomy, competence, and relatedness, as the conceptual framework, students' motivation to take part as facilitators is demonstrated in Tables 1-3.

\section{Discussion}

Our final-year students were provided with an opportunity to undertake important leadership roles as facilitators.

Table 3 Students' motivation in relation to relatedness

Themes relating to relatedness
Students felt a sense of community within the school
Facilitation allowed students to meet and engage their junior
peers in a formal capacity
peers in a formal capacity

Students found facilitation gave them a platform of recognition to recruit participants for their own peer tutoring

Students felt that by facilitating, they became better known to staff

Students were inspired by senior academic staff who have an interest in teaching

Students saw facilitation as a way to engage with clinical school staff

Students felt that by facilitating, they would be provided with future opportunities within the school and hospital

Students found facilitation a way to stay engaged in teaching with the school beyond medical school

By taking part as a facilitator, students felt inspired to help the school in the future

\section{Student comments}

"I think taking part developed a sense of being connected with the clinical school and the other student facilitators as well".

"I had some students in my group that I didn't know, and now they know that I was a facilitator, so it's nice to have that relationship that now we will say good morning when we see each other".

"I liked getting to know the younger years because I don't have that many opportunities to meet them in other circumstances, and I enjoy seeing what kind of creative ideas they come up with in terms of teaching skills and presenting the two exercises that they did".

"It was easier for us to launch our own peer tutoring program with the year 3 students knowing that we were the facilitators in the TT program. We made a good impression".

"I think it's good to make yourself known to people who are in charge of the school or the department. It was nice that the head of school became known to all of us on a more intimate level".

"It was good to get to know the head of school, he's always around, doing important stuff, and this was just nice, to get to see him working with us. I was looking at him and I thought there's someone who does a lot of other things with his life, but obviously still likes it and is still involved in teaching and wants to make the clinical school a better learning environment and that's wonderful".

'It was nice to have recognition from the head of the clinical school and other staff, and to develop a relationship with them so you can keep working within the clinical school, helping out".

"In terms of staff, I think it's really nice that we've started to get to know each other, and I think that builds a nice environment in which to work".

"I think on a logistical level, now that we're known to the administrators and academics, as students who have facilitated the course, you're more likely to be called on to teach. Being a facilitator has provided us with pathways for more opportunities. We'd be more than happy to help with student teaching". "This provides more opportunities for teaching, it builds up the connection a bit more. l'd be more likely to be involved in teaching opportunities as a result of facilitating".

"And if I end up getting an internship at RPA, I think it will be nice to still be in contact with the clinical school. Most people want to come back here to work".

"Being a facilitator definitely makes you want to do more teaching, because then I can improve on and I enjoy teaching".

"I've been inspired to take part more in activities the clinical school organizes because of the rapport we've already established".

"I think being a facilitator inspired me more to want to teach because I hadn't done much teaching before, so doing those small groups sort of sparked the desire to teach". 
Their participation provided a crucial resource to run our TT program. Using SDT as a conceptual framework, this study sought to explore students' motivation to facilitate the TT program for their junior peers.

\section{Autonomy}

A sense of choice is desired by most people, ${ }^{11}$ and students were free to choose whether or not to accept the invitation to facilitate. Although autonomy does not mean working separately from others, ${ }^{12}$ autonomy was fostered by providing students with the opportunity to use their knowledge and prior training in teaching to take responsibility for their own small groups. Some were also given a role within the large group teaching alongside the senior academic staff. By choosing to be facilitators in the TT program, students felt they were able to help shape the quality of teaching for fellow students. ${ }^{13}$

\section{Competence}

Individuals enjoy mastering subjects in which they are engaged. ${ }^{14}$ Reflective practice has the potential to engage and motivate individuals to even higher levels of expertise. ${ }^{15}$ Although our facilitators had already completed the TT course themselves as year 3 students, they felt facilitation in TT provided them with opportunities to practice and reinforce their teaching skills. Certainly, facilitators expressed a sense of achievement and enjoyment in running their own small groups, stating that it presented new challenges to them. For example, our facilitators found it challenging to develop appropriate techniques to correct students' teaching methods during these small-group activities. An optimum level of challenge is important in working toward mastery of a subject, ${ }^{11}$ and our facilitators aspired to improve their professionalism skills in teaching, recognizing this as a graduate attribute that is required in future medical practice.

\section{Relatedness}

A sense of community may be fostered within groups of individuals with similar goals, ${ }^{16,17}$ and medical education involves a process of socialization. ${ }^{18}$ The social context of the TT activities promoted communal engagement, not only among students, but also with senior academic staff. Student facilitators expressed an understanding of how their contributions as facilitators might impact on their school community at Royal Prince Alfred Hospital. ${ }^{6}$ By embedding leadership development in students' hospital-based activities, students could see how their role as facilitators linked to the development of their school, their hospital, and the medical profession as a whole. ${ }^{19}$ Students recognized the importance of teaching in their future medical careers, realizing that teaching formed part of their professional identity.

\section{Limitations}

The major limitation of our study was the small number of participants. The views of these participants may not be generalizable to a wider student population.

\section{Conclusion}

An understanding of students' motivation to participate in leadership roles may help to develop future opportunities for students within our medical school. Importantly, student facilitators conveyed an appreciation of the teaching and supervision responsibilities they will assume in their future careers as medical practitioners. Senior students' motivation to assist with facilitation of the course was largely related to the opportunity to review and build on their own knowledge and skills in teaching practices; the recognition and acknowledgement received from school staff and fellow students; the opportunity to develop these relationships; and the desire to increase their peer-teaching responsibilities. By actively involving our senior students in leadership practices, we were able to not only engage the students, but also develop our student community and contribute to the promotion of a culture of excellence in teaching within the hospital.

\section{Disclosure}

The authors report no conflicts of interest in this work.

\section{References}

1. Burgess A, McGregor D, Mellis C. Medical students as peer tutors: a systematic review. BMC Med Educ. 2014;14:115.

2. van Diggele $C$, Burgess A, Mellis C. Teacher training program for medical students: improvements needed. Adv Med Educ Pract. 2015;6: 265-270.

3. Burgess A, Clark T, Chapman R, Mellis C. Senior medical students as peer examiners in an OSCE. Med Teach. 2013;35(1):58-62.

4. Burgess AW, Roberts C, Black KI, Mellis C. Senior medical student perceived ability and experience in giving peer feedback in formative long case examinations. BMC Med Educ. 2013;13:79.

5. Cushing A, Abbot S, Lothian D, Hall A, Westwood OM. Peer feedback as an aid to learning - what do we want? Feedback. When do we want it? Now! Med Teach. 2011;33:105-112.

6. Swanwick T, McKimm J. Clinical leadership development requires system-wide interventions, not just courses. Clin Teach. 2012;9:89-93.

7. Hill F, Stephens C. Negotiating strategic direction for education staff development: the Southampton experience. Med Teach. 2004;26(7): 645-649.

8. Snowman J, Biehler R. Psychology Applied to Teaching. Boston, New York: Houghton Mifflin Company; 2003.

9. Deci EL, Ryan RM. The "what" and "why" of goal pursuits: human needs and the self-determination of behaviour. Psychol Inq. 2000;11 227-268.

10. Braun V, Clarke V. Using thematic analysis in psychology. Qual Res Psychol. 2006;3(2):77-101. 
11. Lyness JM, Lurie SJ, Ward DS, Mooney CJ, Lambert DR. Engaging students and faculty: implications of self-determination theory for teachers and leaders in academic medicine. BMC Med Educ. 2013;13:151.

12. Schumacher DJ, Englander R, Carraccio C. Developing the master learner: applying learning theory to the learner, the teacher, and the learning environment. Acad Med. 2013;88(11):1635-1645.

13. Swanwick T. Informal learning in postgraduate medical education: from cognitivism to 'culturism'. Med Educ. 2005;39:859-865.

14. Ryff CD, Keyes CL. The structure of psychological well-being revisited. J Pers Soc Psychol. 1995;69:719-727.
15. Gladwell M. Outliers: The Story of Success. New York: Little, Brown and Company; 2008.

16. Pink DH. Drive: The Surprising Truth About What Motivates Us. New York: Riverhead Books; 2009.

17. Baumeister RF, Leary MR. The need to belong: desire for interpersonal attachments as a fundamental human motivation. Psychol Bull. 1995; 117(3):497-529.

18. Dornan T, Bundy C. What can experience add to early medical education? Consensus survey. BMJ. 2004;329(7470):834

19. Lombardo MM, Eichinger RW. Career Architect Development Planner. 3rd ed. Minneapolis: Lominger Limited; 2000.

\section{Publish your work in this journal}

Advances in Medical Education and Practice is an international, peerreviewed, open access journal that aims to present and publish research on Medical Education covering medical, dental, nursing and allied health care professional education. The journal covers undergraduate education, postgraduate training and continuing medical education including emerging trends and innovative models linking education, research, and health care services. The manuscript management system is completely online and includes a very quick and fair peer-review system. Visit http://www.dovepress.com/testimonials.php to read real quotes from published authors.

Submit your manuscript here: http://www.dovepress.com/advances-in-medical-education-and-practice-journal 